\title{
The Strategies of College English Writing
}

\author{
ZHANG Jie \\ University of Chinese Academy of Social Sciences, Beijing, China
}

\begin{abstract}
This paper is to restate the importance of English writing for the Chinese students. The paper will focus on the problems exist in the students writing, such as, the misunderstood topic, the lexical mistakes, the phrase mistakes, and the coherence and unity errors. And the highlight of the paper is to deal with how to overcome the difficulties by emphasizing the elements, such as deciding on a genre of a composition, unity, and coherence for each paragraph and a whole text, the controlling idea in a paragraph and a composition and the logic realization in writing. Using proper and academic words is also necessary element in composing a text.
\end{abstract}

Keywords: topic, academic words, the structure of sentences and cohesion and coherence

\section{The Importance of English Writing}

Writing is very important for all level of learning and examination. Writing is a high level of expression. Human communication starts with oral form of language, the speaking, and written work, the writing. For foreign language education in China writing is compulsory from the senior high school to the Ph.D. education. In every level there is certain teaching syllabus of state or province level, for example for the senior high school students, writing simple letters, notes, or notices, and filling in resume etc. The writing is required to conform to the standard of handwriting, the genre and greetings. And for the college entrance examination the senior are required to write about 80 words to 100 words in 30 minutes. And the basic grammar and sentence structure are evaluated. And the ideas should be clear. ${ }^{1}$

According to the Chinese education bureau's document, the CET 4 or CET 6 has high requirement that students should finish the writing about 150 words in 30 minutes. And some details are mentioned, such as, the first one is ideas express-focus on the topic, the attitude, and opinion. The second one is the text arrangement - different kinds of writing, cohesion, and coherent of t sentence, paragraph, and the whole text. The third one is language application - the diction, grammar and sentence structure and punctuation and logic of the ideas. The last one is to apply writing strategies. ${ }^{2}$

Starting from the college entrance examination, every formal English text, the writing module is unavoidable, like, the Master degree entrance examination, the IELTS writing, the TOEFL examination. Even the Ph.D. candidate entrance examination and course writing is compulsory. Writing is so important for both in-class learning and examinations so the analysis of the writing is necessary, as writing is important element for college students and crucial for the application of English in practice. So the solid foundation for learning of how to learn English well is priority for the students.

ZHANG Jie, Associate Professor, University of Chinese Academy of Social Sciences, Beijing, China.

1 Retrieved from https://wenku.baidu.com/view/58bbf966b84ae45c3b358cb3.html?from=search.

2 Retrieved from_http://cet.neea.edu.cn/res/Home/1704/55b02330ac17274664f06d9d3db8249d.pdf. 


\section{The Problems Exist in the Students Writing}

Writing is so important and students spend much time on practicing it. There are still problems in their writings. The most serious problem is the stray away from the topic that is misunderstanding the topic. The second one is the thesis statement-lack of thesis statement in the composition. The third one is the cohesion of each paragraph and the use of coherent among the paragraphs and in each paragraph. The fourth is the lexical mistakes, and the sentence structures. For the first problem, take the graduate entrance examination as an example. Candidates are required to write a composition of answering the volunteers' questions. Unfortunately some candidates wrote it as asking questions about the volunteering work. This problem caused the total failure of the writing. The second one is that some students cannot state the thesis in the first paragraph, which leads to the whole composition lack of controlling idea. As for the third problem it is particularly important in a writing, but it is sometimes ignored by some students. Some students are feverous about the content and anxious to express the ideas within certain period of time, and hardly to organize the idea logically. The lexical problem could be the auspicious problem in writing although it is not the most serious one. The students usually pay much attention to words, spending more time on memorizing the words. But while the students are writing a composition the words which can be used are only the simple words, the oral form or the non-academic, nothing to say the correct form of the words and sentence structure. With so many problems in the writing, to grasp the proper way and standard of writing is essential for language learners.

\section{The Strategies to Overcome the Difficulties in the Students Writing}

With the problems existing in the students writing, how to avoid the problems and improve the writing ability is impending. Some aspects should be considered for a good piece of writing.

\section{The Genre of the Writing}

The genre of a composition is very important for the students to consider at first step. They can be different kinds of genre in writing, such as the procedure: how something is done; description: what some is like; report: what is a class of thing is like; and explanation: reason why a judgment is made. These genres are identified by their structure and by repeated patters of transitivity, reference, conjunction, etc., so that students writing exposition may be taught to use a thesis-argument-conclusion structure, while undergraduates might produce discussions following issue-point of view-conclusion pattern (Candin \& Hall, 2005).

So the first to consider is to judge the genre of the writing. Be sure about and be familiar with the kind of composition. The different kinds of writing may have different structure and ways of producing the composition. For example, if it is a letter, the format should be included. If it is exposition, the thesis, argument, and conclusion are necessary in the process of the explanation.

\section{Unity of a Paragraph}

Unity is an important element for a good paragraph. For both paragraphs and a whole text controlling idea is very necessary. A paragraph with a single major thought is said to have unity, and this major though is called controlling idea. For a paragraph the controlling idea of a paragraph is usually expressed in a word or group of words, and represented in a topic sentence. And the topic sentence should be extended in the paragraph to achieve a unit of a paragraph. Every supporting sentence must directly explain or prove the main idea. For example, there are three paragraphs; only one paragraph is unity and the other two are not. One discusses two different topics and the other does not have unity because it has sentences that are not related to the main topics. 
Para. 1.

Effect of color.

Colors creates biological reactions in our bodies. These reactions, in turn, can change our behavior. In one study prisoners were put in a pink room, and they underwent a drastic and measurable decrease in muscle strength and hostility within 2.7 seconds. In another study, athletes needing short bursts of energy were exposed to red light. Their muscle strength increased by 13.5 percent, and electrical activity in their arm muscles increased by 5.8 percent. Athlete's need more endurance for longer performance responded best when exposed to blue light. Other studies have shown that the color green is calming. Green was a sacred color to the Egyptians representing the hoe and joy of spring. It is also a sacred color to Muslims. Many mosques and religious temples throughout the world use green (the color of renewal and growth) and blue) the color of heaven) to balance heavenly peace with spiritual growth. To sum up, color influences us in many ways. (Daniels, 2004, p. 10)

Para. 2.

Effect of color.

Colors creates biological reactions in our bodies. These reactions, in turn, can change our behavior. In one study prisoners were put in a pink room, and they underwent a drastic and measurable decrease in muscle strength and hostility within 2.7 seconds. In another study, athletes needing short bursts of energy were exposed to red light. Their muscle strength increased by 13.5 percent, and electrical activity in their arm muscles increased by 5.8 percent. Athlete's need more endurance for longer performance responded best when exposed to blue light. Other studies have shown that the color green is calming. After London's Blackfraris bridge was painted green, the number of suicides decreased by 34 percent. These and other studies clearly demonstrate that color affects not only our moods but also our behaviors as well. (Daniels, 2004, p. 10)

Para. 3.

Effect of color

Colors creates biological reactions in our bodies. These reactions, in turn, can change our behavior. In one study prisoners were put in a pink room, and they underwent a drastic and measurable decrease in muscle strength and hostility within 2.7 seconds. In another study, athletes needing short bursts of energy were exposed to red light. Their muscle strength increased by 13.5 percent, and electrical activity in their arm muscles increased by 5.8 percent. Athlete's need more endurance for longer performance responded best when exposed to blue light. Blue is not a good color for dinnerware, however. Food looks less appetizing when it is served on blue plates, perhaps because very few foods in nature are of that color. Other studies have shown that the color green is calming. After London's Blackfraris bridge was painted green, the number of suicides decreased by 34 percent. These and other studies clearly demonstrate that color affects not only our moods but also our behaviors as well. (Daniels, 2004, p. 10)

After reading the paragraphs, it will be clear that Paragraph 1 does not have unity because it has sentences that are not related to the main idea, while Paragraph 3 does have unity because of two different topics. One is the effect of color and the other is that color blue is not a good color. Only Paragraph 2 has unity.

As the whole text of the controlling idea is to concern the same idea in the text, the controlling idea guides the whole text. Although some examples may cite, they must serve to support the topic. Each paragraph can only be part of the whole text. For example, the topic is "Online Shopping". Different paragraph must be concerning with the controlling idea of online shopping. They would be the different kinds of online shopping, the positive and negative of online shopping, the development of online shopping, the strategies of online shopping, and the enjoyment of online shopping. Of course students may mention the main customers of online shopping; the point cannot the main concern. With achieving the unity for paragraph and a whole text, another element to be cautious is the coherence.

\section{Coherence of a Paragraph}

Coherence means to hold together. For coherence in writing, the sentences must hold together, that is, the 
movement from one sentence to the next must be logical and smooth. There must be no sudden jumps. Every sentence should flow smoothly into the next one. There are four ways to achieve coherence.

They are repeating key nouns, using consistent pronoun, using transition signal to link ideas, and arranging ideas in logical order. ${ }^{3}$

The first way is repeating the key nouns. Repetition is a common way for coherence. It is can also be called a rhetoric way. In a writing, the repetition of key nouns can produce both coherence and literacy of a writing.

When referring to the same noun, repeating key nouns in a writing is essential. And it can also be a kind of rhetoric device for a writing. For example, in a paragraph the key word is gold; the repletion of the key word can be the exact word "gold" and also can be coin. Another example, a boy can be replaced as a young man, a guy, a hero, or a creature, etc., choosing the synonyms according to mood of the paragraph.

The second way is using consistent pronoun. The correct using pronoun is a sign of language development. For a child at first it is difficult to identify the related pronoun and fully grasp the using of consistent pronoun representing the logical thought in expression.

The third way is transition signals to link ideas. There different kinds of transition signals.

\begin{tabular}{|c|c|c|c|c|c|}
\hline $\begin{array}{l}\text { Functions to } \\
\text { introduce }\end{array}$ & Transition phrases & Conjunctive adverbs & $\begin{array}{l}\text { Coordinating } \\
\text { conjunctions }\end{array}$ & $\begin{array}{l}\text { Subordinating } \\
\text { conjunctions }\end{array}$ & Others \\
\hline Additional idea & in addition & $\begin{array}{l}\text { furthermore, } \\
\text { moreover, besides, } \\
\text { also, too }\end{array}$ & and & & another \\
\hline $\begin{array}{l}\text { Opposition or } \\
\text { contrast }\end{array}$ & $\begin{array}{l}\text { on the other hand, in } \\
\text { contrast }\end{array}$ & \begin{tabular}{|l|} 
however, \\
nevertheless, \\
instead, still \\
nonetheless
\end{tabular} & $\begin{array}{l}\text { but } \\
\text { yet, }\end{array}$ & $\begin{array}{l}\text { although, though, } \\
\text { even though, } \\
\text { whereas, while }\end{array}$ & in spite of, despite \\
\hline $\begin{array}{l}\text { A choice or } \\
\text { alternative }\end{array}$ & & & or & if, unless & \\
\hline $\begin{array}{l}\text { To introduce a } \\
\text { restatement or } \\
\text { explanation }\end{array}$ & in fact in deed & & & & \\
\hline To list in order & first, second, ... & & & & the first, the second, ... \\
\hline An example & $\begin{array}{l}\text { for example, } \\
\text { for instance }\end{array}$ & & & & an example of , such as \\
\hline $\begin{array}{l}\text { A conclusion or } \\
\text { summary }\end{array}$ & $\begin{array}{l}\text { clearly in brief } \\
\text { conclusion }\end{array}$ & & & & \\
\hline A result & \begin{tabular}{|l|} 
according to \\
as a result
\end{tabular} & & so & & \\
\hline
\end{tabular}

The application of transition signals is important for coherence. According to language ability the overuse of transition signal is a kind of language deficiency.

The fourth one is arranging ideas in logical order, such as the chronological order, the logical division of ideas, and the comparison/contrast. These methods can help the writing be coherent and logic and be well understood. Only with the unity and coherence of a paragraph a writing can be clear, logic, and readable. If a writing is considered to be well written, diction and sentence structure are also needed.

\section{Diction and Sentence Structure for a Good Writing}

Diction is basic for a good writing, and directly indicates a good writing. The first point is formal and

\footnotetext{
${ }^{3}$ Retrieved from http://club.topsage.com/forum-63-1.
} 
informal. English is rich in vocabulary with multiple origins, among which the long words mainly come from Latin Greek and French. And they are more formal and usually used in the formal style, such as: law document, government paper, and business communication, etc. The informal vocabularies are the words from old English, and usually short and easily understood, for example, purchase vs. buy, utilize vs. use, terminate vs. end, punctual vs. on time, explode vs. bow up, investigate vs. look into. The first ones in the pairs are suitable for the formal and solemn situations ion, while the second ones of the pairs are usually used in an informal writing or daily life. The second point is written or oral. Admittedly the language used in daily life is usually oral language. Secondly what to consider for choosing words is about oral or written words. College English Writing is formal; of course it isn't reach to the frozen style. It is recommended to write with formal and written words. For example, compare the two sentences: The College required all the students to submit their essay by a given time. I have got to hand in my essay by tomorrow. The first sentence is written in style, and the second one is oral style. The college English writing is required to test writing ability rather than oral, so writing for the different kind examinations is required for formal in style. Written works do not use personal pronouns, for example: The sentence like "some action should be taken for environmental protection", is written in style, while the sentence like "we should take some actions to protect the environment" is oral in style. Comparing the two sentences, the first one is suggested in writing. Another feature of written is that the important information in the sentence is put at the end of a sentence. Comparing the two sentences: "It is reported that the post office has received one of letter" and "one of the letters has arrived (but the other one hasn't)", the first sentence is more acceptable in examination writing. As for diction, the use of synonyms is also important. For example, the list of words like: bear, endure, tolerate, stand, and put up with should be used carefully. If it is a formal writing the first three words should be used. If it is an informal writing the two should be used. Written features of writing require that the writer pay attention to the personal pronoun, the position of important information, and the use of synonym (Xu, 2005).

The third point is using words concisely. Conciseness is one of the important features for a good writing. In writing if a meaning can be expressed in a word, then do not use a phrase, such as suddenly vs. all of a sudden, because vs. because of the fact that, although vs. in spite of the fact that. Similarly, phrases are more efficient than clauses considering the conciseness of writing.

The fourth point of diction is the collocation of words. Sometimes the collocation of Chinese and English is different, for example: to acquire knowledge, to get a job, to achieve success, to gain reputation, to attain one's end.

The last point of diction is to avoid using the same words repeatedly. For example the notion of moving forward can be expressed like run, move, turn, roll, whirl, etc.

As for sentences, the most important point is grammatical grammar and the variety of sentences structure. With different sentences structures, rhythms of language can be noticed and sensed. And the beauty of language can be show.

\section{Conclusion}

With the discussion of the importance of English writing and the problems existing in the students writing, some strategies and methods of writing concluded in the paper. The genre is the first to consider, and the unity, the coherence, and the diction are also important in the process of writing. 


\section{References}

Candin, C. N., \& Hall, D. R. (2005). Teaching and reaching writing. Beijing: Foreign Language Teaching and Reaching Press. Daniels, A. (2004). “Curing With Color”, From House to Home. Martin Independent Journal, Novato California, 8-10.

$\mathrm{Xu}$, J. N. \& Ha, H. ( 2005). “ Accurate Words, Appropriate Sentences, Effective Paragraphs”. Liaoning: Dalian Industrial University Press. 